\title{
Statins impact on epigenetics of tumor cells
}

\author{
Murtaza Kulaksiz, Martin Hohenegger \\ From 18th Scientific Symposium of the Austrian Pharmacological Society (APHAR). Joint meeting with the \\ Croatian, Serbian and Slovenian Pharmacological Societies. \\ Graz, Austria. 20-21 September 2012
}

\section{Background}

Histones are basic proteins and are modified by diverse post-translation modifications such as acetylation, methylation, phosphorylation and ubiquitinylation. These epigenetic modifications are important regulatory processes in proliferation, survival, differentiation and motility. The epigenetic gene regulation occurs in DNA methylation at DNA level and histone modification or chromatin remodelling at protein level. Several enzymes, like DNA methyltransferases (DNMTs), histone methyltransferases (HMTs), histone demethylases (HDMs), histone acetyltransferases (HATs) and histone deacetylases (HDACs), are able to modify the chromatin. The histone modifications lead to alterations in chromatin and form heterochromatin or euchromatin, which activates or silences transcription. Statins are used successfully in the treatment of hypercholesterolemia and inhibit 3hydroxy-3-methylglutaryl-CoA (HMG-CoA) reductase. HMG-CoA reductase is the rate-limiting enzyme of the mevalonate pathway. The synthesis of isoprenoids such as farnesylpyrophosphate (FPP) and geranylgeranylpyrophosphate (GGPP) is reduced by statins by inhibition of the HMG-CoA reductase. These isoprenoid intermediates are involved in post-translational modifications of Ras, Rho and Rac, which are typical for G proteins and have crucial roles in cancer cells.

\section{Methods}

Western blot analysis was performed to quantify acetylation status of histones in SH-SY5Y and RD cell lines.

\section{Results}

SH-SY5Y and RD cells were treated and incubated with increasing concentrations of simvastatin. The lysates were separated in a cytosolic and nuclear fraction.

\footnotetext{
* Correspondence: martin.hohenegger@meduniwien.ac.at

Institute of Pharmacology, Center for Physiology and Pharmacology, Medical University of Vienna, 1090 Vienna, Austria
}

acetylated proteins were detected mainly in the nuclear fraction. Interestingly, the pattern of acetylation did not change very much upon statin exposure in the cytosol. However, in the nuclear fraction simvastatin extracts were acetylated to a greater extent.

\section{Conclusions}

The data presented here suggest that simvastatin can affect histones and their post-translational modifications. Enhanced acetylation of nuclear proteins induced by simvastatin might be interpreted as an inhibition of a HDAC activity or/and as an increased HAT-mediated acetylation in SH-SY5Y and RD cells.

\section{Acknowledgements}

This work was supported by the Herzfeldersche Familienstiftung and the Austrian Science Fund FWF (P-22385).

Published: 17 September 2012

doi:10.1186/2050-6511-13-S1-A64

Cite this article as: Kulaksiz and Hohenegger: Statins impact on epigenetics of tumor cells. BMC Pharmacology and Toxicology 2012 13(Suppl 1):A64.

Submit your next manuscript to BioMed Central and take full advantage of:

- Convenient online submission

- Thorough peer review

- No space constraints or color figure charges

- Immediate publication on acceptance

- Inclusion in PubMed, CAS, Scopus and Google Scholar

- Research which is freely available for redistribution 